\title{
Raising the profile of fairness and justice in medical practice and policy
}

\author{
Raanan Gillon
}

Justice, one of the four Beauchamp and Childress prima facie basic principles of biomedical ethics, is explored in two excellent papers in the current issue of the journal. The papers stem from a British Medical Association (BMA) essay competition on justice and fairness in medical practice and policy. Although the competition was open to (almost) all comers, of the 235 entries both the winning paper by Alistair Wardrope ${ }^{1}$ and the highly commended runner-up by Zoe Fritz and Caitríona $\mathrm{Cox}^{2}$ were written by practising doctors-a welcome indication of the growing importance being accorded to philosophical reflection about medical practice and practices within medicine itself. Both papers are thoroughly thought provoking and represent two very different approaches to the topic. Each deserves a careful read.

The competition was a component of a BMA 2019/2020 'Presidential project' on fairness and justice and asked candidates to 'use ethical reasoning and theory to tackle challenging, practical, contemporary, problems in health care and help provide a solution based on an explained and defended sense of fairness/justice'.

In this guest editorial I'd like to explain why, in 2018 on becoming president-elect of the BMA, I chose the theme of justice and fairness in medical ethics for my 20192020 Presidential project-and why in a world of massive and ever-increasing and remediable health inequalities biomedical ethics requires greater international and interdisciplinary efforts to try to reach agreement on the need to achieve greater 'health justice' and to reach agreement on what that commitment actually means and on what in practice it requires.

First, some background. As president I was offered the wonderful opportunity to pursue, with the organisation's formidable assistance, a 'project' consistent with the BMA's interests and values. As a hybrid of general medical practitioner and philosopher/medical ethicist, and as a firm defender of the Beauchamp and Childress

Department of Primary Care and Public Health, Imperial College London, London, UK

Correspondence to Professor Raanan Gillon, Department of Primary Care and Public Health, Imperial College London, London W6 8RP, UK;

raanan.gillon@imperial.ac.uk four principles approach to medical ethics, ${ }^{3}$ I chose to try to raise the ethical profile of justice and fairness within medical ethics.

My first objective was to ask the BMA to ask the World Medical Association (WMA) to add an explicit commitment 'to strive to practise fairly and justly throughout my professional life' to its contemporary version of the Hippocratic Oath-the Declaration of Geneva ${ }^{4}$ - and to the companion document the International Code of Medical Ethics. ${ }^{5}$ The stimulus for this proposal was the WMA's addition in 2017 of the principle of respect for patients' autonomy. Important as that addition is, it is widely perceived (though in my own view mistakenly) as being too much focused on individual patients and not enough on communities, groups and populations. The simple addition of a commitment to fairness and justice would provide a 'balancing' moral commitment.

\section{ADDING THE FOURTH PRINCIPLE}

It would also explicitly add the fourth of those four prima facie moral commitments, increasingly widely accepted by doctors internationally. Two of them-benefiting our patients (beneficence) and doing so with as little harm as possible (nonmaleficence)-have been an integral part of medical ethics since Hippocratic times. Respect for autonomy and justice are very much more recent additions to medical ethics. The WMA, having added respect for autonomy to the Declaration of Geneva, should, I proposed, complete the quartet by adding the 'balancing' principle of fairness and justice.

Since the Declaration is unlikely to be revised for several years, it seems likely that the proposal to add to it an explicit commitment to practise fairly and justly will have to wait. However, an explicit commitment to justice and fairness has, at the BMA's request, been added to the draft of the International Code of Medical Ethics and it seems reasonable to hope and expect that it will remain in the final document.

Adding a commitment to fairness and justice is the easy part! Few doctors would on reflection deny that they ought to try to practise fairly and justly. It is far more difficult to say what is actually meant by this. Two additional components of my Presidential project-the essay competition and a conference (which with luck will have been held, virtually, shortly before publication of this editorial)—sought to help elucidate just what is meant by practising fairly and justly.

One of the most striking features of the essay competition was the readiness of many writers to point to injustices in the context of medical practice and policy and describe ways of remedying them, but without giving a specific account of justice and fairness on the basis of which the diagnosis of injustice was made and the remedy offered.

Wardrope's winning essay comes close to such an approach by challenging the implied premise that an account of justice and fairness must provide some such formal theory. In preference, he points to the evident injustice and unsustainability of humans' degradation of 'the Land' and its atmosphere and its inhabitants and then challenges some assumptions of contemporary philosophy and ethics, especially what he sees as their anthropocentric and individualistic focus. Instead, he invokes Leopold Aldo's 'Land Ethic' (as well as drawing in aid Isabelle Stenger's focus on 'the intrusion of Gaia'). In his thoughtful and challenging paper, he seeks to refocus our ethics-including our medical ethics and our sense of justice and fairness - on mankind's exploitative threat, during this contemporary 'anthropocene' stage of evolution, to the continuing existence of humans and of all forms of life in our 'biotic community'. As remedy, the author, allying his approach to those of contemporary virtue ethics, recommends the beneficial outcomes that would be brought about by a sense of fairness and justice- a developed and sensitive 'ecological conscience' as he calls it-that embraces the interests of the entire biotic community of which we humans are but a part.

Fritz and Cox pursue a very different and philosophically more conventional approach to the essay competition's question and offer a combination and development of two established philosophical theories, those of John Rawls and Thomas Scanlon, to provide a philosophically robust and practically beneficial methodology for justice and fairness in medical practice and policy. Briefly summarised, they recommend a twostage approach for healthcare justice. First, those faced with a problem of fairness or justice in healthcare or policy should use Thomas Scanlon's proposed contractualist approach whereby reasonable people seek solutions that they and others could not 'reasonably reject'. This stage would involve committees of decision-makers and representatives of relevant stakeholders looking at the immediate and longer term impact on 
existing stakeholders of proposed solutions. They would then check those solutions against substantive criteria of justice derived from Rawls' theory (which, via his theoretical device of the 'veil of ignorance', Rawls and the authors argue that all reasonable people can be expected to accept!). The Rawlsian criteria relied on by Fritz and Cox are equity of access to healthcare; the 'difference principle' whereby avoidable inequalities of primary goods can only be justified if they benefit the most disadvantaged; the just savings principle, of particular importance for ensuring intergenerational justice and sustainability; and a criterion of increased openness, transparency and accountability.

It would of course be naïve to expect a single universalisable solution to the question 'what do we mean by fairness and justice in health care?' As the papers by Wardrope $^{1}$ and Fritz and Cox ${ }^{2}$ demonstrate, there can be very wide differences of approach in well-defended accounts. My own hope for my project is to emphasise the importance first of committing ourselves within medicine to practising fairly and justly in whatever branch we practise; and then to think carefully about what we do mean by that and act accordingly.

\section{FOLLOWING ARISTOTLE}

For my own part, over 40 years of looking, I have not yet found a single substantive theory of justice that is plausibly universalisable and have had to content myself with Aristotle's formal, almost content-free but probably universalisable theory, according to which equals should be treated equally and unequals unequally in proportion to the relevant inequalities-what some health economists refer to as horizontal and vertical justice or equity. ${ }^{6}$

Beauchamp and Childress in their recent eighth and 'perhaps final' edition of their foundational 'Principles of biomedical ethics', acknowledge that ' $\mathrm{t}]$ he construction of a unified theory of justice that captures our diverse conceptions and principles of justice in biomedical ethics continues to be controversial and difficult to pin down'.

They still cite Aristotle's formal principle (though with less explanation than in their first edition back in 1979) and they still believe that this formal principle requires substantive or 'material' content if it is to be useful in practice. They then describe six different theories of justice-four 'traditional' (utilitarian, libertarian, communitarian and egalitarian) and two newer theories, which they suggest may be more helpful in the context of health justice, one based on capabilities and the other on actual well-being.

They again end their discussion of justice with their reminder that 'Policies of just access to health care, strategies of efficiencies in health care institutions, and global needs for the reduction of health-impairing conditions dwarf in social importance every other issue considered in this book' ....... 'every society must ration its resources but many societies can close gaps in fair rationing more conscientiously than they have to date' [emphasis added]. And they go on to stress their own support for 'recognition of global rights to health and enforceable rights to health care in nation-states'.

For my own part I recommend, perhaps less ambitiously, that across the globe we extract from Aristotle's formal theory of justice a starting point that ethically requires us to focus on equality and always to treat others as equals and treat them equally unless there are moral justifications for not doing so. Where such justifications exist we should say what they are, explain the moral

${ }^{\mathrm{i}}$ See reference 3 , especially pp vii, 267, 313 and all of chapter 7 on justice. assumptions that justify them and, to the extent possible, seek the agreement of those affected.

Funding The author has not had any specific grant for this research from any funding agency in the public, commercial or not-for-profit sectors.

Competing interests The author has no competing interests.

Patient consent for publication Not required.

Ethics approval Not required

Provenance and peer review Commissioned; internally peer reviewed.

(c) Author(s) (or their employer(s)) 2020. No commercial re-use. See rights and permissions. Published by BMJ.

Check for updates

To cite Gillon R. J Med Ethics 2020;46:789-790.

Received 29 October 2020

Accepted 29 October 2020

Published Online First 20 November 2020

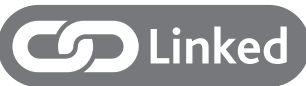

http://dx.doi.org/10.1136/medethics-2020-106855

- http://dx.doi.org/10.1136/medethics-2020-106853

J Med Ethics 2020;46:789-790.

doi:10.1136/medethics-2020-107039

ORCID iD

Raanan Gillon http://orcid.org/0000-0002-1237-4937

\section{REFERENCES}

1 Wardrope A. Health justice in the Anthropocene: medical ethics and the land ethic. J Med Ethics 2020;46:791-6.

2 Fritz Z, Cox CL. Integrating philosophy, policy and practice to create a just and fair health service. J Med Ethics 2020;46:797-802.

3 Beauchamp T, Childress J. Principles of biomedical ethics. $8^{\text {th }}$ ed. New York, Oxford: Oxford University Press, 2019.

4 Declaration of Geneva. World Medical association. Ferney-Voltaire, France. current version, 2017. Available: https://www.wma.net/policies-post/wma-declarationof-geneva/ [Accessed 26 Oct 2020].

5 International Code of Medical Ethics. World Medical association. Ferney-Voltaire, France. current version, 2006. Available: https://www.wma.net/policies-post/wmainternational-code-of-medical-ethics/ [Accessed 26 Oct 20].

6 Tao Y, Henry K, Zou Q, et al. Methods for measuring horizontal equity in health resource allocation: a comparative study. Health Econ Rev 2014;4(1):10. 